\title{
Public Perceptions of Facebook's Libra Digital Currency Initiative: Text Mining on Twitter
}

\author{
Chen Ye \\ Purdue University Northwest \\ chenye@pnw.edu
}

\author{
Lin Zhao \\ Purdue University Northwest \\ lzhao@pnw.edu
}

\begin{abstract}
Large corporations in the financial and technology sectors are increasingly interested in digital currencies, and central bank digital currencies are being actively researched around the globe. In this study, we analyzed the public discourse conducted through the social media platform Twitter concerning Facebook's Libra digital currency initiative. Text mining of tweets posted during the one-month period around the official announcement of the digital currency project revealed that the majority of the public have a neutral sentiment toward the proposed digital currency. However, those with positive attitudes outnumbered those perceiving the digital currency initiative as negative, and the negative sentiment mainly stemmed from anger and anxiety. Through topical modeling analysis using latent Dirichlet allocation, we identified eight themes in the public discourse related to Facebook Libra. The study provides an early exploratory assessment of factors facilitating and hindering user adoption of one of the most important practical applications of blockchain technology.
\end{abstract}

\section{Introduction}

On June 18, 2019, Facebook announced its digital currency project, Libra. This followed months of public speculation on the company's potential blockchainrelated initiatives stemming from its recently formed group devoted to blockchain technology. According to the Libra white paper [1], the digital currency will be pegged to a basket of bank deposits and short-term government securities denominated in sovereign currencies including the dollar, euro, franc, pound and yen. Therefore, unlike pure cryptocurrencies such as Bitcoin, Ethereum and Litecoin, Libra will be a stablecoin whose value is determined by the underlying assets rather than by the market. The Libra digital currency is intended to be used for making day-to-day transactions globally, and it serves as the centerpiece of Facebook's strategy on blockchain technology and global payment.

Since the announcement, government officials and central bankers around the globe have expressed concerns and oppositions. These apprehensions are not due to doubts about digital currency as a viable technology, but rather over the threat that a successful Libra could impose on sovereign currencies [2]. In fact, many nations have engaged in research and testing of their own central bank digital currencies (CBDCs) [3]. Government officials in China have publicly acknowledged Libra to be the catalyst for accelerated development of the country's national digital currency, which is known as digital currency electronic payment (DCEP) [4]. At the time of this writing, DECP is undergoing testing in real life payment scenarios. Furthermore, MIT Technology Review listed digital currency, the earliest practical application of blockchain technology, as one of the 10 breakthrough technologies of 2020 [5].

A digital currency that is oriented toward retail payment is clearly a technology targeting the broadest user base possible. Therefore, it is valuable to understand the opinions, feelings, and concerns of the general public toward a digital currency. Research has shown that social media provides a rich source of information in understanding public sentiment toward various social and economic issues [6-10]. As one of the most widely used social media platforms, Twitter enables users to express their opinions and feelings in short text-based posts called tweets. Various studies have collected and analyzed tweets related to a wide range of topics. These have included major news events such as the Brazilian presidential impeachment [6], social movements such as Black Lives Matter [7], emerging technologies such as the Internet of Things [8, 9], and upcoming products launches from well-known companies, such as Apple's iPhone 6 [10].

One of the most commonly used techniques for mining social media data, sentiment analysis (also known as opinion mining) is "the process of quantifying 
the emotional value in a series of words or text, to gain an understanding of the attitudes, opinions and emotions (positive, negative and neutral) expressed" [11]. Scholars have also applied text mining techniques to identify major topics or themes emerging from the public discourse on Twitter [e.g., 6-8]. Compared to responses collected through traditional methods (such as surveys and interviews using prescribed questions), social media posts are spontaneous and allow for much larger data sets [12]. In this study we use Facebook's Libra digital currency project as the research setting and use sentiment analysis and topical modeling techniques to examine tweets concerning the project following its initial announcement. We aim to answer the following research questions:

RQ1: What are the public sentiments in response to a digital currency initiative?

RQ2: What are the main topics in the public discourse concerning a digital currency initiative?

\section{Related Work and Research Background}

\subsection{Related Work}

The growing popularity of social media such as Twitter has provided scholars with a venue for collecting and analyzing large quantity of usergenerated content [13]. Researchers have applied text mining techniques on collections of tweets to discover information that is of value in different areas of academic interest. To help answer their respective research questions, two types of information are often inferred from tweets: user sentiments and topics of discourse. Studies have considered user sentiments and emotions expressed in tweets, quantified through sentiment analysis, to be important indicators of psychological state and predictors of behavior. Wang et al. [12] analyzed over two billion tweets using the linguistic inquiry and word count (LIWC) tool to reveal how people's positive emotion and thoughts (e.g., food, friends, fun, leisure) and negative emotion and concerns (e.g., stress, work, money, health) fluctuated over the course of a week. Stieglitz and Linh [14]'s examination of tweets discussing two political elections in Germany suggests that messages expressing stronger sentiments are retweeted more often and more quickly. Koohikamali and Gerhart [15] also found that during a social crisis, tweets with stronger sentiment extremity are more likely to be retweeted and upvoted.

A further body of research has employed manual or computational approaches to discover the latent topics or themes contained in the public discourse on a specific issue on Twitter. Lundgaard et al. [7] manually classified 2,050 tweets regarding the \#BlackLivesMatter movement into five categories (raising awareness, offline activism, anti-authorities, victimization, and collaboration). Similarly, through manual content analysis, Brünker et al. [16] found sharing of personal information, reference, call for action, and testimony to be the main content categories in a sample of 1,271 tweets related to the \#metoo movement. In their study of 6,874 tweets posted by six traumatic brain injury patients, Brunner et al. [17] handcoded the tweets into six categories: supporting others, society and culture, connecting with others, life after the illness, knowledge, and advocacy. The authors also performed co-occurrence network analysis programmatically to capture word clusters within the tweets. The results are in line with the themes identified through manual content analysis.

Information system researchers have also combined sentiment and topical analyses in studies of tweets on a variety of topics. In the domain of public health, Boit and El-Gayer [18] found that Twitter conversations on malaria were more likely to be negative than positive, and that sadness and disgust were the top two emotions expressed. They also identified different emergent topics within the subsets of different sentiments. Regarding crisis management by major companies, Stieglitz el al. [19] observed that negative opinions far outweighed positive ones among users discussing Volkswagen's Dieselgate scandal. Further analysis classified some of the tweets from the company into two crisis response strategies (apology and ingratiation). In the context of new technologies, Bian et al. [8] and Liu and Zhang [9] concluded that the public attitude on Twitter toward the Internet of Things was predominately positive. Both studies also extracted latent topics (e.g., "smart technologies", "connected device", and "big data") from the dataset using latent Dirichlet allocation (LDA) [8] and latent semantic analysis [9], respectively. Concerning specific products from large technology providers, Kim et al. [10] assessed consumer sentiments toward Apple's iPhone 6 and Samsung's Galaxy S5 on Twitter. The authors categorized the tweets according to specific phone features mentioned, and they also applied machine learning to classify each tweet based on whether it expressed an intention to purchase the product.

To our knowledge, there have been few social media studies addressing public opinions toward initiatives related to blockchain and digital currency. Shin et al. [20] examined frequently retweeted messages during initial coin offering (ICO) of the Stratis cryptocurrency. Human coding identified different topics during the preICO, ICO, and post-ICO periods. As the two digital currency projects differ drastically in terms of the intended purpose of the coin, the technical mechanism 
of coin issuance, and the public profile of the issuing company, we expect to gain different insights from the case of Facebook Libra.

\subsection{Research Background}

Ever since the creation of Bitcoin by Satoshi Nakamoto, digital currencies have been the most wellunderstood practical application of blockchain technology. As of early November 2020, over 7,000 cryptocurrencies are listed on CoinMarketCap.com, with a total market cap of over 470 million USD. Most of the existing cryptocurrencies are governed by small communities of open source developers or startup companies. In recent years, large corporations have started to recognize the potential value of digital currencies on global remittance, a market projected by the World Bank to reach 746 billion USD in 2020. In February 2019, JP Morgan Chase announced a plan to issue JPM Coin, a stablecoin backed by the US dollar to be used for interbank payments. JPM Coin will operate as a token on the Quorum blockchain, an open source blockchain forked from Ethereum.

Facebook's Libra, on the other hand, is intended to be used mainly as a global payment system for everyday financial transactions such as retail purchases. In fact, it was referred to as "GlobalCoin" in news media prior to its official announcement. As is the case with Bitcoin and Ethereum, Libra will function as a cryptocurrency with its own blockchain, which will be permissioned at the beginning and will later transition to be permissionless. The Libra blockchain will also support smart contracts with a newly invented programming language called Move. Like other asset-back stablecoins such as Tether, new Libra coins will be minted rather than being created through mining.

Although Facebook is responsible for the development of Libra, the governing body of the digital currency will be a newly formed nonprofit Libra Association headquartered in Switzerland. The Libra Association will have 100 institutions as founding members, and Facebook claimed that their Calibra subsidiary will be a regular member with the same voting power as other partners. The association is also open to other nonprofits (e.g., Mercy Corps).

In addition to wanting Libra to be the internet's native currency, Facebook declared an ambitious goal for the new digital currency: to bring digital payment and other basic financial services to unbanked people across the world. Currently, there are an estimated 1.7 billion people worldwide who do not have a bank account or credit card, and existing digital payment services such as Venmo, Paypal, and WeChat Pay all rely on traditional banking to function.

\section{Research Methods}

\subsection{Data Collection}

We searched for and extracted tweets written in English through the Twitter premium API using the rtweet package, which is developed in $\mathrm{R}$ programming language. We used the phrase "Facebook Libra" and related hashtags as search terms to avoid unrelated messages. Our search includes the 29-day period from June 17, 2019 (the day before Facebook officially announced Libra) to July 15, 2019 (four weeks afterwards).

\subsection{Data Analysis}

In our analysis we used LIWC, a widely used language analysis tool [21] for "studying the various emotional, cognitive, and structural components present in individuals' verbal and written speech samples" [22]. The operation logic of LIWC text analysis is straightforward: calculate the percentage of words out of the total number of words in the target text that match a dictionary. As the most recent development, LIWC 2015 has made significant improvement in the dictionary and software features. It is now capable of capturing more than $86 \%$ of the words people use in oral and written English, including words frequently used on social media. LIWC 2015 reports 41 constructs for psychological processes, including affect, cognition, and perception. Negative emotion and positive emotion are categorized as two constructs under affective processes. Negative emotion also has three sub-constructs: anxiety, anger, and sadness. For example, LIWC reports $25 \%$ in the positive emotion category based on the assessment of a simple sentence: "I like the flower." This is because "like" is the only word that expresses positive emotion out of the total of four words in the text. Many studies have verified the internal and external validity of LIWC in emotional expression identification [23, 24, 25].

Since this study focused on the affective dimensions of each tweet, the percentage of the words which expressed positive emotion (e.g., love, nice) and negative emotion (e.g., hurt, ugly) generated by LIWC 2015 were converted to continuous scores by multiplying them by 100 . Recent research $[14,26]$ suggested that the direction and strength of the sentiment can be measured by the sentiment polarity of each tweet using the following formula:

$$
\text { polarity }=\text { positive }+ \text { negative }
$$

where positive denoted the positive sentiment scored from 0 to 100 and negative denoted the negative sentiment scored from 0 to -100 . As a result, the 
sentiment polarity falls within the range [-100, 100], and 0 represents neutral sentiment.

To mine the corpus for the latent topics of discourse concerning Libra, we used LDA, an algorithm for probabilistic topic modeling. "Topic models are algorithms for discovering the main themes that pervade a large and otherwise unstructured collection of documents." [27]. Blei [27] provided a comprehensive survey article explaining the principles of LDA. As an illustrative example, Blei applied LDA to a set of 17,000 articles from the journal Science. One of the topics emerged from the statistical analysis relates to computers, with "computer", "models", "information", "computers", and "system" as the topical words in order of declining probabilities of appearing in articles discussing computer-related issues.

\section{Results}

\subsection{Dataset}

The search yielded a corpus including 248,776 tweets and retweets. Examination of the dataset showed that almost all the tweets were related to the digital currency project. Figure 1 illustrates the trend of the volume of tweets over time. As expected, most of the discussions occurred immediately after the official announcement on June 18, 2019. The volume of tweets declined sharply two days after the announcement. Close examination of the tweets on June 17 suggests that some details of the upcoming announcement, including the term "Libra", had been made public through different channels (e.g., "Mercado Libre exec says the firm has partnered with Facebook on the Libra cryptocurrency project").



Figure 1: Daily volume of Libra related tweets

A total of 121,960 unique Twitter users joined the conversation. Figure 2 shows the distribution of the total number of tweets by user account creation date. All account age groups participated actively in the discussions.

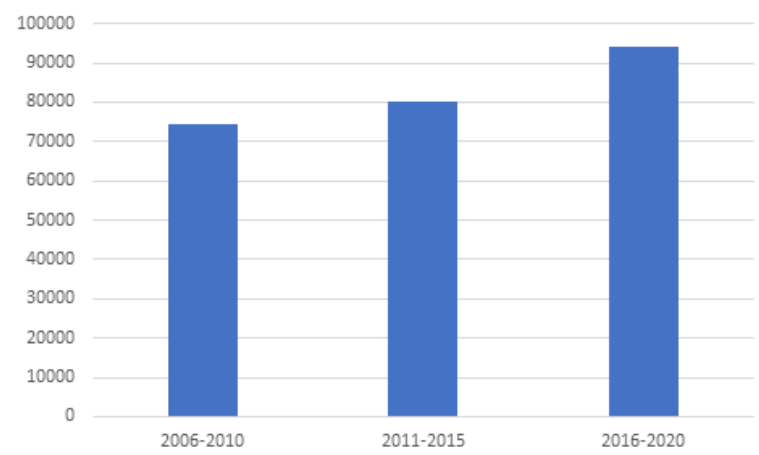

Figure 2: Total number of tweets by account creation date

\subsection{Data Pre-processing}

Since there was no mechanism available in Twitter premium API to prevent the collection of duplicate tweets, we followed the steps in the data pre-processing strategy proposed by $[10,28]$. After removing URLs, usernames, \#s before hashtags, retweets, and duplicated tweets, the final data sample contained 70,461 tweets for further analysis. As the existing social media literature suggests, data pre-processing was necessary because the main purpose of our study was to explore unique opinions presented by the public.

\subsection{Public Sentiments Toward Libra}

For a closer look at tweets featuring positive and negative sentiments associated with Facebook Libra, a few samples are shown in Table 1. In terms of sentiment polarity (Figure 3), 23\% of all the tweets showed positive sentiments, $13 \%$ were negative, and $64 \%$ were neutral. If neutral tweets were excluded, positive emotion dominated the public discourses on Facebook Libra by accounting for about $63 \%$ of the total sentiments. Furthermore, a paired-samples t-test was conduct to confirm that the sentiment of tweets was significantly more positive $(\mathrm{MD}=2.20, t(27533)=$ $37.34, p=0.00)$.

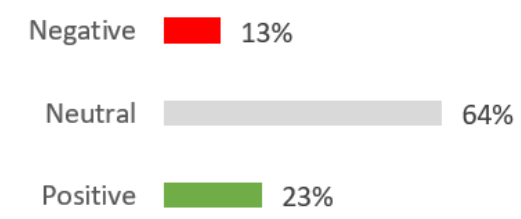

Figure 3: Sentiment distribution 
Table 1: Sample tweets with different sentiments

\begin{tabular}{|l|ll|}
\hline Sentiment & \multicolumn{1}{|c|}{ Sample tweets } \\
\hline Positive & 1. & $\begin{array}{l}\text { A very interesting first grasp on } \\
\text { @Facebook's \#Libra coin. } \\
\text { Thank you for that }\end{array}$ \\
& 2. & $\begin{array}{l}\text { \#Libra project looks awesome! I } \\
\text { believe it can potentially have } \\
\text { dramatic impact on connecting } \\
\text { (billions of people with the next } \\
\text { generation of money. }\end{array}$ \\
\hline Neutral & 1. $\begin{array}{l}\text { Facebook launches a new } \\
\text { cryptocurrency called Libra }\end{array}$ \\
& 2. $\begin{array}{l}\text { Facebook's on-platform Libra } \\
\text { currency could have major } \\
\text { impacts - but will it change how } \\
\text { brands use the platform? }\end{array}$ \\
\hline Negative & $\begin{array}{l}\text { 1. } \\
\text { Libra sucks. I wouldn't trust } \\
\text { Libra, Zuck or anything } \\
\text { Facebook related with any of my } \\
\text { financial information. }\end{array}$ \\
& 2. $\begin{array}{l}\text { FACEBOOK COUNTRY } \\
\text { That's exactly what \#Libra does: } \\
\text { it sucks all the value you already } \\
\text { generated, and puts it into a } \\
\text { token which is not controlled by } \\
\text { you, and you don't even realize } \\
\text { how toxic the whole situation } \\
\text { is... }\end{array}$ \\
&
\end{tabular}

Statistical analysis on negative emotions indicated that the average scores for sadness were significantly lower than those for anger $(\mathrm{MD}=0.77, t(27553)=$ $34.42, p=0.00)$ and anxiety $(\mathrm{MD}=0.74, t(27533)=$ $34.21, p=0.00)$, and there was no significant difference in the scores for anger and the scores for anxiety $(\mathrm{MD}=$ $0.03, t(27533)=1.31, p=0.19)$.

\subsection{Geographic Distribution}

The default setting of user location feature on Twitter is "off" and it can only be enabled by the user. We were able to find 38,083 tweets with identifiable user locations. This provided valuable insights by establishing the geographic context in which the tweeter was engaged in public dialogue about Libra. As illustrated in Table 2, tweeters from the USA dominated the discourse by posting $44.4 \%$ of total tweets, followed by the UK $(14.97 \%)$, India $(5.51 \%)$, Canada $(5.19 \%)$ and Australia $(2.87 \%)$. In addition, four non-native English-speaking European countries and one African county also actively participated in the discussions.
Table 2: Distribution of tweets by country

\begin{tabular}{cccc} 
Rank & Country & \# of Tweets & \% of Total \\
\hline 1 & USA & 16909 & $44.40 \%$ \\
\hline 2 & UK & 5702 & $14.97 \%$ \\
\hline 3 & India & 2098 & $5.51 \%$ \\
\hline 4 & Canada & 1976 & $5.19 \%$ \\
\hline 5 & Australia & 1094 & $2.87 \%$ \\
\hline 6 & Germany & 794 & $2.08 \%$ \\
\hline 7 & Switzerland & 689 & $1.81 \%$ \\
\hline 8 & Nigeria & 667 & $1.75 \%$ \\
\hline 9 & France & 620 & $1.63 \%$ \\
\hline 10 & Netherlands & 587 & $1.54 \%$ \\
\hline
\end{tabular}

\subsection{Latent Topical Modeling with Latent Dirichlet Allocation}

We used a word cloud to highlight popular terms (Figure 4). Since the size and color of each word is proportional to its frequency in the tweets, the most prominent words can be identified quickly in a single glance.

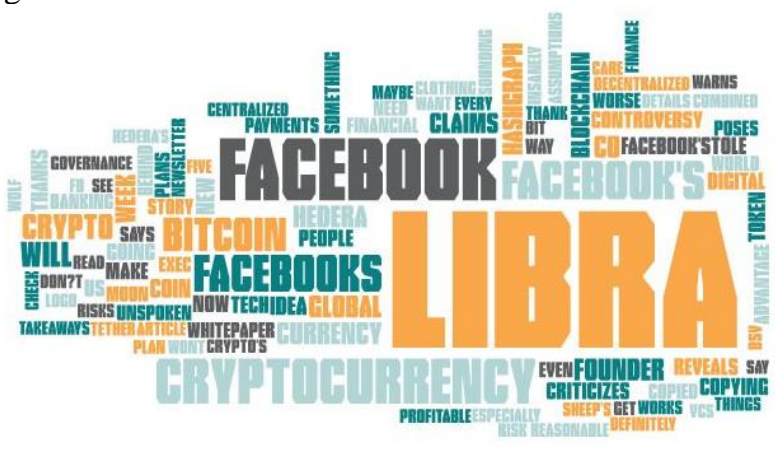

Figure 4: Word cloud depicting the frequency of keywords

We applied LDA analysis to the pre-processed dataset with the list of stop words supplied with the machine learning from language toolkit (MALLET) (available at mallet.cs.umass.edu). We found that additional words - "Facebook", "Libra", "cryptocurrency", "crypto", and "coin" - need to be included in the list to avoid these words dominating multiple topics and preventing the true latent topics from emerging. Through an iterative process of adjusting parameters of the LDA algorithm combined with human judgments [8], we identified eight distinct latent topics. These topics, with sample tweets in their original unaltered form (italics added), include: 
1. Digital currency: with "currency" and "digital" as the two dominant words under this topic, the messages revolved around the nature of Libra being a digital currency. Many users were simply announcing the project to their followers, e.g., "Facebook is moving forward with creating a digital currency. They say it'll be as easy to send their currency 'Libra' as sending a text." Some also offered their own prediction: "Libra will be the gateway drug for digital currency to the average joe."

2. Blockchain: the underlying technology of most digital currencies was frequently brought up in Libra related tweets and formed a latent topic. In addition to "blockchain," words such as "technology" and "fintech" also coappeared with lower probabilities. One tweet predicts: "After Facebook's Libra, i bet Bezos would be making plans for a similar blockchain launch". Another post states: “@aantonop: Is Facebook's Libra a real blockchain? No. Will it compete against \#Bitcoin and truly open, public blockchains? Never."

3. Bitcoin: the name of the most well-known cryptocurrency appeared in a significant portion of the discussions. Top cooccurring words included "price", "real", and "ethereum." Some posts obviously came from the so-called Bitcoin Maximalists: "Bitcoin is the real value for the people, nor Facebook's Libra. we have one faketoshi, no need for a second wannabe Robin Hood - It's not about hating on Libra, it's about moving things in the right light." Others were interested in the impact of Libra on Bitcoin's price: “\#Bitcoin prices up $240 \%$ since January... some of this is due to \#Facebook's \#Libra \#cryptocurency."

4. Banks: the implications of a digital currency on banks was clearly in the minds of many posters. For example, "What will the banks think about Libra?? It will be very interesting!! \#libra \#Facebook \#banks \#Calibra" and "Facebook's Libra shows it's time for central banks to step up." Some tweets also reflected the news headlines by featuring the reactions from bank officials: "BaFin Head Urges Global Bank Standards in Response to Facebook's Libra" and "European governments and central banks have objections to \#Facebook cryptocurrency \#Libra."

5. Regulation: reactions from government officials and regulators were the focus of messages under this latent topic. In addition to "regulation", probable words also included "congress", "government" and "Trump". Some posts foresaw the potential regulatory hurdles: "Smart move by Facebook. New crypto currency called "libra" would be launch mid next year 2020 but faces heavy regulations bcoz of his past record." Others echoed headline news: "It seems like Facebook's Libra cryptocurrency has ruffled a few feathers. Several Congresspeople immediately took up arms and pushed for a moratorium on the Libra project while they presumably work on hastily passing regulations on cryptocurrency. Now Trump is joining the party."

6. Trust: with "data", "privacy" and "concerns" as the other leading words in this cluster, some users expressed their distrust of Facebook, e.g., "Facebook have already shown that they can't be trusted with our data - while also owning WhatsApp and Instagram. It's already easy enough to send money. I hope Libra fails" and "If you don't trust Facebook to manage the News Feed, why would you trust it to construct a financial system?"

7. Project specifics: words describing specifics of the project such as "whitepaper", "calibra", "wallet", and "launch" tended to coappear, e.g., "Facebook released whitepaper for Libra. And announced crypto wallet calibra!"

8. People: most messages under this topic offered opinions on how "people" would respond to Libra. Other coappearing words included "world" and "power". A sample post declares: "Many people in the second and third world have Facebook and absolutely don't care about data protection. they have sooo many other problems we don't have to think of... so $i$ can absolutely understand, that they prefer convenience in other parts of life. Libra will succeed."

While not emerging as independent topics in our analysis, a set of words including "payments", "money", "Zuckerberg", "financial", "news", "global", "exchange", "plan", and "market" appeared as probable across multiple latent topics. Each of these terms represents a significant element of the collective public mindset regarding Facebook Libra.

\section{Discussion}

The objective of this study was to perform an exploratory assessment of public perceptions of a digital currency initiative from a large company. We collected and examined micro-blogs related to Facebook's Libra digital currency project posted on Twitter during a fourweek period around the official public announcement.

The results indicate that a high-profile digital currency initiative spurred strong interest from a diverse user base on a social media platform. On the day of the announcement, the volume of posts averaged 37.5 tweets per minute. People outside of the USA accounted for $56 \%$ of the users contributing to the public discourse in English, demonstrating the global impact of a digital currency initiative.

\subsection{Public Sentiments Toward Facebook Libra}

In response to the first research question, we investigated over 240,000 tweets mentioning Facebook Libra which were posted directly before and after the 
initial announcement for 29 continuous days. As was expected based on the existing literature [10, 29], the volume of tweets fluctuated over time and was closely associated with the important events that happened due to this new initiative.

After data pre-processing, affective dimensions on positive and negative emotions expressed by tweets were analyzed using LIWC, an empirically validated text analytics tool for sentiment analysis. The sentiment scores calculated by LIWC were used to measure the direction and strength of positive and negative sentiments through polarity. The results clearly indicate that neutral tweets dominated the conversations about Facebook Libra. This is similar to previous perceptual studies on digital currency [30]. This finding is particularly meaningful because it suggests that most of the general public is still not predisposed to love or hate a digital currency. Instead, they remain neutral and open to the debate.

Excluding the neutral tweets, the statistical comparison show that a significantly higher level of positive emotions is implied in the public discourse, suggesting that the most sentimental audiences felt optimistic about the future of Facebook Libra. A further exploration found that the negative sentiment in the data set could be attributed to anxiety and anger, but not sadness, since a lot of uncertainties and risks are seriously considered and involved in the early stage of creating a new digital currency.

\subsection{Topics of the Public Discourse on Facebook Libra}

Our second research question concerns the topics and themes existing in the public discourse regarding a digital currency. Findings of the topical modeling analysis suggest that the public - the potential adopters of Facebook Libra - recognize it as a digital currency and tool for making payments. Manifestations of traditional technology adoption factors such as perceived usefulness (usefulness in making payments) and perceived ease of use (ease of sending and receiving payments) continue to drive adoption of blockchainrelated technologies [31]. However, there are major hurdles to overcome for a digital currency to gain wide acceptance. First, approval from regulators is a crucial consideration. Navigating multiple jurisdictions and satisfying the varying legal requirements regarding consumer privacy, counterterrorism, anti-money laundering (AML) and know your customer (KYC) are a major challenge for a digital currency intended for cross-border use. Second, distrust of the entity issuing the digital currency may lead to consumer resistance [32]. Prior violations of user privacy by a company, the public image of a famous founder, or the reputation of a government will significantly impact the perceived trustworthiness of a digital currency. Third, there is a loyal user base of existing cryptocurrencies who may not welcome digital currencies from large companies or governments. Furthermore, users accustomed to using features of existing digital currencies (e.g., developing and deploying smart contracts in the Solidity programming language on the Ethereum blockchain) may be reluctant to switch to an alternative [33].

\section{Concluding Remarks}

Large corporations in the financial and technology sectors are increasingly interested in digital currencies [34]. CBDC is viewed by many in the payment industry as a technological breakthrough [35], and the prospect of a digital USD is under active debate [36]. On the other hand, research on what facilitates and hinders public acceptance of digital currencies has been scarce, and most existing research has focused on Bitcoin [37]. As one of the first investigations of a digital currency issued by a large company, the present study contributes to the literature by extracting the public perceptions of the digital currency expressed on social media. The findings shed light on some of the key issues in the public mindset concerning a digital currency aimed at broad retail usage. We also hope this exploratory study will draw more scholarly attention to digital currencies, as they are one of the blockchain applications that could potentially have profound economic, political, and societal impacts.

There are several limitations of the present study that also point to opportunities for future research. First, we selected the time period of one month following the official announcement of Libra for data collection. Many aspects of the project have evolved since that time in response to various outside influences, and public perceptions have likely also changed over time. Researchers have also suggested that topical modeling be used to track the changing themes of public discourse longitudinally [23]. The conclusions from investigating a private sector digital currency may not be completely applicable to CBDCs with official backing from governments. The present study provides an early exploration of factors that could influence users' adoption of a digital currency. Researchers are encouraged to conduct quantitative assessment of behavioral models under suitable empirical settings as digital currencies enter mainstream usage.

\section{References}


[1] https://libra.org/en-US/white-paper/, accessed July 1, 2020.

[2] R. Browne, "Facebook's Cryptocurrency Faced with Regulatory Warnings from Global Central Bankers", CNBC.com, June 20, 2019.

[3] C. Ye, and K. Desouza, "The Current Landscape of Central Bank Digital Currencies", TechTank, Brookings Institution, December 13, 2019.

[4] D. Pan, "How the People's Bank of China Became a CBDC Leader", coindesk.com, May 11, 2020.

[5] A. Regalado, "Digital Money", technologyreview.com, Feb. 26, 2020.

[6] F. B. de França, D. Goya, and C. C. Penteado, "Analysis of the Twitter Interactions During the Impeachment of Brazilian President", Proceedings of the 51st Hawaii International Conference on System Sciences, 2018.

[7] D. Lundgaard, L. Razmerita, and C.-W. Tan. "Emergent Collaboration on Twitter: A Case Study of the\# BlackLivesMatter Movement", Proceedings of the 51st Hawaii International Conference on System Sciences, 2018.

[8] J. Bian, K. Yoshigoe, A. Hicks, J. Yuan, Z. He, M. Xie, and F. Modave, "Mining Twitter to Assess the Public Perception of the "Internet of Things"" PLOS ONE, 11(7), 2016.

[9] Z. Liu, and M. Zhang. "Analysing Online Platform Users' Attitudes toward Internet of Things", Proceedings of the 22nd Pacific Asia Conference on Information Systems, 2018.

[10] Y. Kim, R. Dwivedi, J. Zhang, and S. R. Jeong, "Competitive Intelligence in Social Media Twitter: iPhone 6 vs. Galaxy S5", Online Information Review, 40(1), 2016, pp. 42-61.

[11] S. Redhu, S. Srivastava, B. Bansal, and G. Gupta, "Sentiment Analysis Using Text Mining: A Review", International Journal on Data Science and Technology, 4(2), 2018, pp. 49-53.

[12] W. Wang, I. Hernandez, D. A. Newman, J. He, and J. Bian, "Twitter Analysis: Studying US Weekly Trends in Work Stress and Emotion," Applied Psychology, 65(2), 2016, pp. 355-378.

[13] D. A. Broniatowski, M. J. Paul, and M. Dredze, "Twitter: Big Data Opportunities,” Science, 345(6193), 2014, pp. 148.

[14] S. Stieglitz, and D.-X. Linh, "Emotions and Information Diffusion in Social Media-Sentiment of Microblogs and Sharing Behavior", Journal of Management Information Systems, 29(4), 2013, pp. 217-248.

[15] M. Koohikamali, and N. Gerhart, "Yaks versus Tweets: Sentiment Discrepancy During a Social Crisis", In Proceedings of the 51st Hawaii International Conference on System Sciences, 2018.

[16] F. Brünker, M. Wischnewski, M. Mirbabaie, and J. Meinert, "The Role of Social Media During Social Movements - Observations from the \#metoo Debate on
Twitter", Proceedings of the 53rd Hawaii International Conference on System Sciences, 2020.

[17] M. Brunner, S. Palmer, L. Togher, S. Dann, and B. Hemsley, "Content Analysis of Tweets by People with Traumatic Brain Injury (TBI): Implications for Rehabilitation and Social Media Goals", Proceedings of the 52nd Hawaii International Conference on System Sciences, 2019.

[18] J. Boit, and O. El-Gayar, "Topical Mining of Malaria Using Social Media. A Text Mining Approach”, Proceedings of the 53rd Hawaii International Conference on System Sciences, 2020.

[19] S. Stieglitz, M. Mirbabaie, and T. Potthoff, "Crisis Communication on Twitter during a Global Crisis of Volkswagen-The Case of "Dieselgate"", Proceedings of the 51st Hawaii International Conference on System Sciences, 2018.

[20] S. I. Shin, J. B. Kim, D. Hall, and T. Lang, "What Information Propagates among the Public when an Initial Coin Offering (ICO) is Initiated? A theory-driven approach", Proceedings of the 52nd Hawaii International Conference on System Sciences, 2019.

[21] J. W. Pennebaker, M. E. Francis, and R. J. Booth, "Linguistic Inquiry and Word Count: LIWC 2001", Lawrence Erlbaum Associates, Mahway, 71(2001), 2001.

[22] J. W. Pennebaker, R. L. Boyd, K. Jordan, and K. Blackburn, "The Development and Psychometric Properties of LIWC2015", 2015.

[23] E. O. Bantum, and J. E. Owen, "Evaluating the Validity of Computerized Content Analysis Programs for Identification of Emotional Expression in Cancer Narratives". Psychological Assessment, 21(1), 2009, pp. 79-88.

[24] J. Kahn, R. M. Tobin, A. E. Massey, and J. A. Jennifer, "Measuring Emotional Expression with the Linguistic Inquiry and Word Count", The American journal of psychology, 120, 2007, pp. 263-86.

[25] Y. Tausczik, and J. Pennebaker, "The Psychological Meaning of Words: LIWC and Computerized Text Analysis Methods", Journal of Language and Social Psychology, 29, 2010, 24-54.

[26] M. Salehan, and D. J. Kim, "Predicting the performance of online consumer reviews: A sentiment mining approach to big data analytics", Decision Support Systems, 81(January 2016), pp. 30-40.

[27] D. M. Blei, "Probabilistic Topic Models", Communications of the ACM, 55(4), 2012, pp. 7784.

[28] E. Abedin, H. Jafarzadeh, and S. Akhlaghpour, "Opinion Mining on Twitter: A Sentiment Analysis of the Iran Deal", PACIS 2018 Proceeding, 220, 2018.

[29] D. Choi, and P. Kim, "Sentiment Analysis for Tracking Breaking Events: A Case Study on Twitter", Intelligent Information and Database Systems, 7803, 2013. 
[30] E. Horton, C. Parker and L. J. Pharris, "Student Perceptions of Digital Currency", The International Journal of Business and Management, 4(2), 2018, pp. 273-282.

[31] P. Grover, A. K. Kar, M. Janssen, and P. V. Ilavarasan, "Perceived Usefulness, Ease of Use and User Acceptance of Blockchain Technology for Digital Transactions-Insights from User-Generated Content on Twitter", Enterprise Information Systems, 13(6), 2019, pp. 771-800.

[32] H. Chemingui, and H. B. Lallouna, "Resistance, Motivations, Trust and Intention to Use Mobile Financial Services", International Journal of Bank Marketing, 31(7), 2013, pp. 574-592.

[33] C. Ye, and R. Potter, "The Role of Habit in Post-Adoption Switching of Personal Information Technologies: An Empirical Investigation", Communications of the Association for Information Systems, 28(1), 2011, pp. 585-610.

[34] T. Wright, "Visa Files Patent Application for Digital Currency”, CoinTelegraph.com, May 15, 2020.

[35] E. David, "CBDC is the Most Important Trend in Payment Says Visa Crypto Chief', CoinTelegraph.com, July 5, 2020.

[36] T. Koffman, "U.S. Moves Closer to Digital Dollar", Forbes.com, July 1, 2020.

[37] W. Presthus, and N. O. O'Malley, "Motivations and Barriers for End-User Adoption of Bitcoin as Digital Currency", Procedia Computer Science, 121, 2017, pp. 89-97. 